\title{
The day of the week effect in the cryptocurrency market
}

\author{
Guglielmo Maria Caporale ${ }^{\mathrm{a}, *}$, Alex Plastun ${ }^{\mathrm{b}, 1}$ \\ ${ }^{a}$ Department of Economics and Finance, CESifo and DIW Berlin, Brunel University London, UB8 3PH, United Kingdom \\ ${ }^{\mathrm{b}}$ Sumy State University, Ukraine
}

\section{A R T I C L E I N F O}

\section{Keywords:}

Efficient Market Hypothesis

Day of the week effect

Cryptocurrency

Bitcoin

Anomaly

Trading strategy

JEL classification:

G12

C63

\begin{abstract}
A B S T R A C T
This paper examines the day of the week effect in the cryptocurrency market using a variety of statistical techniques (average analysis, Student's t-test, ANOVA, the Kruskal-Wallis test, and regression analysis with dummy variables) as well as a trading simulation approach. Most crypto currencies (LiteCoin, Ripple, Dash) are found not to exhibit this anomaly. The only exception is BitCoin, for which returns on Mondays are significantly higher than those on the other days of the week. In this case the trading simulation analysis shows that there exist exploitable profit opportunities; however, most of these results are not significantly different from the random ones and therefore cannot be seen as conclusive evidence against market efficiency.
\end{abstract}

\section{Introduction}

There exists a vast literature analyzing calendar anomalies (the day of the week effect, the Turn of the Month Effect, the Month of the Year Effect, the January Effect, the Holiday Effect, the Halloween Effect etc.), and whether or not these can be seen as evidence against the Efficient Market Hypothesis (EMH - see, e.g., Fama, 1965; Samuelson, 1965; Jensen, 1978). However, with one exception (Kurihara and Fukushima, 2017) to date no study has analysed such issues in the context of the cryptocurrency market - this being a newly developed market, it might still be relatively inefficient and it might offer more opportunities for making abnormal profits by adopting trading strategies exploiting calendar anomalies. We focus in particular on the day of the week effect, and for robustness purposes apply a variety of statistical methods (average analysis, Student's $t$-test, ANOVA, the Kruskal-Wallis and Mann-Whitney tests, and regression analysis with dummy variables) as well as a trading robot approach that replicates the actions of traders to examine whether or not such an anomaly gives rise to exploitable profit opportunities.

The paper is structured as follows: Section 2 briefly reviews the literature on the day of the week effect; Section 3 outlines the empirical methodology; Section 4 presents the empirical results; Section 5 offers some concluding remarks.

\section{Literature review}

The day of the week effect (concerning statistically significant differences between returns on different days of the week) was one of the first calendar anomalies to be examined. Fields (1931) showed that the best trading day of the week is Saturday. Cross (1973) provided evidence of statistical differences in Friday-Monday data in the US stock market. French (1980) reported negative returns on Mondays. Further studies found evidence of a positive Friday/negative Monday pattern (see Gibbons and Hess, 1981; Rogalski,

\footnotetext{
* Corresponding author.

E-mail address: Guglielmo-Maria.Caporale@brunel.ac.uk (G.M. Caporale).

${ }^{1}$ Author Alex Plastun gratefully acknowledges financial support from the Ministry of Education and Science of Ukraine (0117U003936).
} 
Table 1

Capitalisation of the cryptocurrency market (25.09.2017).

\begin{tabular}{|c|c|c|c|c|c|}
\hline$\#$ & Name & Market cap & Price & Circulating supply & Data starts from \\
\hline 1 & Bitcoin & $\$ 61,661,715,957$ & $\$ 3717.96$ & $16,584,825$ ВТС & 28 apr 2013 \\
\hline 2 & Ethereum & $\$ 27,047,930,739$ & $\$ 285.32$ & $94,798,247$ ETH & 07 aug 2015 \\
\hline 3 & Bitcoin Cash & $\$ 7,048,650,600$ & $\$ 424.34$ & $16,611,013 \mathrm{BCH}$ & 23 jul 2017 \\
\hline 4 & Ripple & $\$ 6,743,378,097$ & $\$ 0.175866$ & $38,343,841,883 \mathrm{XRP}^{*}$ & 04 aug 2013 \\
\hline 5 & Dash & $\$ 2,662,327,218$ & $\$ 351.38$ & $7,576,753$ DASH & 14 feb 2014 \\
\hline 6 & Litecoin & $\$ 2,546,042,771$ & $\$ 47.97$ & $53,077,832$ LTC & 28 apr 2013 \\
\hline 7 & NEM & $\$ 1,978,722,000$ & $\$ 0.219858$ & 8,999,999,999 XEM* & 01 apr 2015 \\
\hline 8 & IOTA & $\$ 1,449,700,153$ & $\$ 0.521563$ & $2,779,530,283$ MIOTA* & 13 jun 2017 \\
\hline 9 & Monero & $\$ 1,360,521,393$ & $\$ 89.94$ & $15,127,056 \mathrm{XMR}$ & 21 may 2014 \\
\hline 10 & Ethereum Classic & $\$ 1,004,178,222$ & $\$ 10.48$ & $95,822,190$ ETC & 24 jun 2016 \\
\hline
\end{tabular}

* Cryptocurrency Market Capitalizations. URL: https://coinmarketcap.com/coins/.

1984; Smirlock and Starks, 1986, etc.).Other studies on the stock market include Sias and Starks (1995), Hsaio and Solt (2004), and Caporale et al. (2016), whilst commodity markets were analysed by Singal and Tayal (2014), and the FOREX by Caporale et al. (2017).Ariel (1990), Fortune (1998) and Schwert (2003) all reported evidence against the Monday effect in developed markets, but this anomaly still appears to exist in many emerging markets (Caporale and Plastun, 2017).

The cryptocurrency market is rather young but sufficient data are now available to examine its properties. Dwyer (2014), Cheung et al. (2015) and Carrick (2016) show that it is much more volatile than other markets. Brown (2014) provides evidence of short-term price predictability of the BitCoin. The inefficiency of the BitCoinmarket is also documented by Urquhart (2016), whilst Bartos (2015) reports that this market immediately reacts to the arrival of new information and can therefore be characterised as efficient. Halaburda and Gandal (2014) analyse correlations in daily closing prices.

However, so far the only study examining anomalies in this market is due to Kurihara and Fukushima (2017), who focus exclusively on the BitCoin, which is not necessarily representative of the cryptocurrency market as a whole. The present paper aims to fill this gap in the literature by providing much more extensive evidence on the day of the week effect in this market.

\section{Data and methodology}

We examine daily data for 4 cryptocurrencies, choosing those with the highest market capitalization and the longest data span (2013-2017), namely BitCoin, LiteCoin, Ripple and Dash. The data source is CoinMarketCap (https://coinmarketcap.com/coins/). More information on the cryptocurrency market is provided in Table 1 below.

Returns are computed as follows:

$$
R_{i}=\left(\frac{\text { Close }_{i}}{\operatorname{Close}_{i-1}}-1\right) \times 100 \%,
$$

where $R_{i}$ - returns on the ith day in \%;

Close $_{i}$ - close price on the $i$ th day;

Close $_{i-1}-$ close price on the $(i-1)$ th day.

Average analysis provides preliminary evidence on whether there are differences between returns for the different days of the week. Both parametric and non-parametric tests are carried out given the evidence of fat tails and kurtosis in returns. The Null Hypothesis (H0) in each case is that the data belong to the same population, a rejection of the null suggesting the presence of an anomaly.

We carry out Student's t-test, ANOVA, Kruskal-Wallis and Mann-Whitney tests for the whole sample, and also for sub-samples in order to make comparisons between periods that might be characterised by an anomaly and the others.

Student's $t$-tests are carried out for the null hypothesis that returns on all days of the week belong to the same population; a rejection of the null implies a statistical anomaly in the price behaviour on a specific day of the week. Given the size of our dataset, it is legitimate to argue that normality holds, and therefore these are valid statistical tests. To provide additional evidence one more method is used, namely ANOVA analysis. The main advantages of these methods are their simple interpretation, robustness and overall ease of use. Their main disadvantage is that they do not consider the possibility of non-normal distributions of the data.

To take this into account, a number of additional non-parametric tests can be used, such as the Kruskal-Wallis and Mann-Whitney tests. Their key advantage is that they do not require any assumptions about the distribution of the population. The main limitation of the Mann-Whitney test is that it can only be used for 2 groups. Therefore we also carry out the Kruskal-Wallis tests that also allow testing for 3 groups or more. The reason for carrying out both non-parametric and parametric tests is to check for robustness.

We also run multiple regressions including a dummy variable to identify the day of the week effect:

$$
Y_{t}=a_{0}+a_{1} D_{1 t}+a_{2} D_{2 t}+\ldots+b_{n} D n_{t}+\varepsilon_{t}
$$

where $Y_{t}$ - return in period $t$. 
$a_{n}-$ mean return on the $\mathrm{n}$ day of the week.

$D_{n t^{-}}$a dummy variable for the $\mathrm{n}$ day of the week, equal to 1 for observations corresponding to that day and to 0 otherwise. $\varepsilon_{t}-$ error term for period $t$.

The size, sign and statistical significance of the dummy coefficients provide information about possible anomalies.

If an anomaly is detected we then apply a trading robot approach that simulates the actions of a trader according to an algorithm (trading strategy) with the aim of establishing whether or not that anomaly gives rise to exploitable profit opportunities, which could be seen as evidence against market efficiency. This is a programme in the MetaTrader terminal that has been developed in MetaQuotes Language 4 (MQL4) and used for the automation of analytical and trading processes. Trading robots (called experts in MetaTrader) allow to analyse price data and manage trading activities on the basis of the signals received.

If a strategy results in the number of profitable trades $>50 \%$ and/or total profits from trading are $>0$, then we conclude that there is a market anomaly. The results are presented in the "Report" in Appendix A. The most important indicators given in the "Report" are:

- Total net profit - financial result of all trades. This parameter represents the difference between "Gross profit" and "Gross loss".

- Expected payoff - mathematical expectation of a win. This parameter represents the average profit/loss for one trade. It also shows the expected profitability/unprofitability of the next trade.

- Total trades - total number of trade positions.

- Bars in test - the number of observations used for testing.

The findings are summarised in the "Graph" section of the "Report": this represents the account balance and general account status considering open positions. The "Report" also provides full information about all the simulated transactions and their financial results.

To make sure that the results we obtain are statistically different from the random trading ones we carry out $t$-tests. We chose this approach instead of carrying out z-tests because the sample size is less than 100. A $t$-test compares the means from two samples to see whether they come from the same population. In our case the first is the average profit/loss factor of one trade applying the trading strategy, and the second is equal to zero because random trading (without transaction costs) should generate zero profit.

The null hypothesis (H0) is that the mean is the same in both samples, and the alternative (H1) that it is not. The computed values of the $t$-test are compared with the critical one at the $5 \%$ significance level. Failure to reject H0 implies that there are no advantages from exploiting the trading strategy being considered, whilst a rejection suggests that the adopted strategy can generate abnormal profits.

An example of the $t$-test is presented in Table 2.

As can be seen there is no evidence of statistically significant difference in terms of total net profits relative to the random trading case, and therefore no market inefficiency is detected.

\section{Empirical results}

The complete set of results can be found in Appendix B. The average analysis (Figs. B.1-B.4) provides preliminary evidences in favor of a day of the week anomaly in the dynamics of BitCoin and LiteCoin, whilst in the cases of Ripple and Dash it is unclear whether or not this is present. The results of the parametric and non-parametric tests are reported in Appendices C-F) and summarized in Table 3.

There is clear evidence of an anomaly only in the case of BitCoin. The next step is to apply a trading simulation approach. First we design appropriate trading rules for the days when long or short positions, respectively, should be opened (see Table 4 for details).

As can be seen most of the tests above provide evidence in favour of the presence of an anomaly in Monday returns for BitCoin. To make sure that this is not the result of the base effect we extend the analysis in order to be able to compare provide returns on Mondays with average returns on all other days of the week except Mondays and Sundays. The results are presented in Appendix G. Most of them (average analysis, $t$-tests and ANOVA analysis, regression analysis with dummy variables) confirm the existence of statistically significant differences between the two sets of returns, more specifically they indicate the presence of abnormally high

Table 2

Example of the $t$-test for the trading strategy effectiveness evaluation: BitCoin testing in 2016.

\begin{tabular}{ll}
\hline Parameter & Value \\
\hline Number of the trades & 51 \\
Total profit & 837 \\
Average profit per trade & 59 \\
Standard deviation & 16 \\
$t$-test & 107 \\
$t$ critical $(0,95)$ & 1,23 \\
Null hypothesis & 1,78 \\
\hline
\end{tabular}


Table 3

Overview of the results for the cryptocurrency market.

\begin{tabular}{|c|c|c|c|c|c|}
\hline Cryptocurrency/methodology & Average analysis & Student's $t$-test & ANOVA & Kruskal -Wallis test & Regression analysis with dummies \\
\hline BitCoin & + & + & + & + & + \\
\hline LiteCoin & + & - & - & - & - \\
\hline Ripple & - & - & - & + & - \\
\hline Dash & - & - & - & + & - \\
\hline
\end{tabular}

Table 4

Anomalies by day for BitCoin.

\begin{tabular}{|c|c|c|c|c|c|c|}
\hline Day of the week & Average analysis & $t$-test & ANOVA & Kruskal -Wallis test & Regression analysis & Overall \\
\hline Monday & + & + & + & + & + & 5 \\
\hline Tuesday & - & - & - & + & - & 1 \\
\hline Wednesday & + & - & - & - & + & 2 \\
\hline Thursday & - & - & - & - & - & 0 \\
\hline Friday & - & - & - & - & + & 1 \\
\hline Saturday & - & - & - & + & - & 1 \\
\hline Sunday & - & - & - & + & - & 1 \\
\hline
\end{tabular}

Table 5

Summary of the trading simulation results.

\begin{tabular}{|c|c|c|c|c|c|c|}
\hline Parameter & Full sample & 2013 & 2014 & 2015 & 2016 & 2017 \\
\hline Profit trades (\% of total) & 60 & 75 & 39 & 60 & 59 & 71 \\
\hline Number of the trades & 245 & 52 & 52 & 52 & 51 & 38 \\
\hline Total profit & 16,990 & 3730 & -315 & 1076 & 837 & 11,662 \\
\hline Average profit per trade & 69 & 72 & -6 & 21 & 16 & 307 \\
\hline Standard deviation & 555 & 341 & 228 & 84 & 107 & 1288 \\
\hline$t$-test & 2.01 & 1.56 & -0.13 & 1.96 & 1.23 & 1.48 \\
\hline$t$ critical $(0,95)$ & 1.78 & 1.78 & 1.78 & 1.78 & 1.78 & 1.78 \\
\hline Null hypothesis & rejected & confirmed & confirmed & rejected & confirmed & confirmed \\
\hline
\end{tabular}

returns on Mondays, i.e. of a day of the week effect in the case of Bitcoin.

Since the anomaly occurs on Mondays (when returns are much higher than on the other days of the week) the trading strategy will be the following: open long positions on Monday and close them at the end of this day. The trading simulation results are reported in Table 5.

In general this strategy is profitable, both for the full sample and for individual years, but in most cases the results are not statistically different from the random trading case, and therefore they do not represent evidence of market inefficiency.

\section{Conclusions}

This paper examines the day of the week effect in the cryptocurrency market focusing on BitCoin, LiteCoin, Ripple and Dash. Applying both parametric and non-parametric methods we find evidence of an anomaly (abnormal positive returns on Mondays) only in the case of BitCoin. Further, using a trading simulation approach we show that a trading strategy based on this anomaly is profitable for the whole sample (2013-2017): it generates net profit with probability $60 \%$ and these results significantly differ from the random ones. However, in the case of individual years the opposite conclusions are reached. On the whole, there is no conclusive evidence that the cryptocurrency market is inefficient.

\section{Supplementary materials}

Supplementary material associated with this article can be found, in the online version, at doi:10.1016/j.frl.2018.11.012.

\section{Appendix A}

Tables A1 and A2, Graph A1. 
Table A1

Example of trading strategy testing report.

\begin{tabular}{|c|c|c|c|c|c|}
\hline \multicolumn{2}{|l|}{ Symbol } & \multicolumn{4}{|l|}{ BTCUSD (1 Lot $=10$ BTC) } \\
\hline Period & & Daily (D1) 2013.01.01 00:00-2017. & $.2200: 00(2013.01 .0$ & $-2017.12 .31)$ & \\
\hline Parameters & & Lots $=1$ & & & \\
\hline Bars in test & 2423 & Ticks modelled & 63,927 & Modelling quality & $\mathrm{n} / \mathrm{a}$ \\
\hline Mismatched charts errors & 0 & & & & \\
\hline Initial deposit & 10,000 & & & Spread & 2 \\
\hline Total net profit & 16,990 & Gross profit & $35,137.7$ & Gross loss & $-18,147.7$ \\
\hline Profit factor & 1.94 & Expected payoff & 69.35 & & \\
\hline Absolute drawdown & 849.6 & Maximal drawdown & $6322.60(22.68 \%)$ & Relative drawdown & $39.54 \%(5983.00)$ \\
\hline \multirow[t]{2}{*}{ Total trades } & 245 & Short positions (won \%) & $0(0.00 \%)$ & Long positions (won \%) & $245(60.00 \%)$ \\
\hline & & Profit trades (\% of total) & $147(60.00 \%)$ & Loss trades (\% of total) & $98(40.00 \%)$ \\
\hline Largest & & profit trade & 3811.8 & loss trade & -4079.2 \\
\hline Average & & profit trade & 239.03 & loss trade & -185.18 \\
\hline Maximum & & consecutive wins (profit in money) & $9(475.80)$ & consecutive losses (loss in money) & $6(-803.50)$ \\
\hline Maximal & & consecutive profit (count of wins) & $8541.80(5)$ & consecutive loss (count of losses) & $-4165.80(2)$ \\
\hline Average & & consecutive wins & 2 & consecutive losses & 2 \\
\hline
\end{tabular}

Table A2

Statement (fragment).

\begin{tabular}{|c|c|c|c|c|c|c|c|c|c|}
\hline$\#$ & Time & Type & Order & Size & Price & $\mathrm{S} / \mathrm{L}$ & $\mathrm{T} / \mathrm{P}$ & Profit & Balance \\
\hline 1 & 07.01.2013 0:00 & buy & 1 & 1 & 13.47 & 0 & 0 & & \\
\hline 2 & 07.01.2013 23:59 & close & 1 & 1 & 13.59 & 0 & 0 & 1.2 & $10,001.2$ \\
\hline 3 & 14.01.2013 0:00 & buy & 2 & 1 & 14.21 & 0 & 0 & & \\
\hline 4 & $14.01 .201323: 59$ & close & 2 & 1 & 14.3 & 0 & 0 & 0.9 & $10,002.1$ \\
\hline 5 & 21.01.2013 0:00 & buy & 3 & 1 & 15.72 & 0 & 0 & & \\
\hline 6 & 21.01.2013 23:59 & close & 3 & 1 & 16.8 & 0 & 0 & 10.8 & $10,012.9$ \\
\hline 7 & 28.01.2013 0:00 & buy & 4 & 1 & 17.84 & 0 & 0 & & \\
\hline 8 & 28.01.2013 23:59 & close & 4 & 1 & 18.72 & 0 & 0 & 8.8 & $10,021.7$ \\
\hline 9 & 04.02.2013 0:00 & buy & 5 & 1 & 20.62 & 0 & 0 & & \\
\hline 10 & 04.02.2013 23:59 & close & 5 & 1 & 20.43 & 0 & 0 & -1.9 & $10,019.8$ \\
\hline 11 & 11.02.2013 0:00 & buy & 6 & 1 & 23.99 & 0 & 0 & & \\
\hline 12 & 11.02.2013 23:59 & close & 6 & 1 & 24.65 & 0 & 0 & 6.6 & $10,026.4$ \\
\hline 13 & 18.02.2013 0:00 & buy & 7 & 1 & 26.92 & 0 & 0 & & \\
\hline 14 & 18.02.2013 23:59 & close & 7 & 1 & 26.95 & 0 & 0 & 0.3 & $10,026.7$ \\
\hline 15 & 25.02 .2013 0:00 & buy & 8 & 1 & 29.91 & 0 & 0 & & \\
\hline 16 & 25.02.2013 23:59 & close & 8 & 1 & 30.4 & 0 & 0 & 4.9 & $10,031.6$ \\
\hline 17 & 04.03.2013 0:00 & buy & 9 & 1 & 34.52 & 0 & 0 & & \\
\hline 18 & 04.03.2013 23:59 & close & 9 & 1 & 36.15 & 0 & 0 & 16.3 & $10,047.9$ \\
\hline 19 & 11.03.2013 0:00 & buy & 10 & 1 & 46.02 & 0 & 0 & & \\
\hline 20 & 11.03.2013 23:59 & close & 10 & 1 & 48.4 & 0 & 0 & 23.8 & $10,071.7$ \\
\hline 21 & 18.03.2013 0:00 & buy & 11 & 1 & 47.42 & 0 & 0 & & \\
\hline 22 & 18.03.2013 23:59 & close & 11 & 1 & 51.6 & 0 & 0 & 41.8 & $10,113.5$ \\
\hline 23 & 25.03.2013 0:00 & buy & 12 & 1 & 71.52 & 0 & 0 & & \\
\hline 24 & 25.03.2013 23:59 & close & 12 & 1 & 73.6 & 0 & 0 & 20.8 & $10,134.3$ \\
\hline 25 & 01.04.2013 0:00 & buy & 13 & 1 & 93.05 & 0 & 0 & & \\
\hline 26 & 01.04.2013 23:59 & close & 13 & 1 & 104 & 0 & 0 & 109.5 & $10,243.8$ \\
\hline 27 & 08.04.2013 0:00 & buy & 14 & 1 & 162.32 & 0 & 0 & & \\
\hline 28 & 08.04.2013 23:59 & close & 14 & 1 & 187.5 & 0 & 0 & 251.8 & $10,495.6$ \\
\hline 29 & 15.04.2013 0:00 & buy & 15 & 1 & 90.02 & 0 & 0 & & \\
\hline 30 & 15.04.2013 23:59 & close & 15 & 1 & 82.39 & 0 & 0 & -76.3 & $10,419.3$ \\
\hline 31 & 22.04.2013 0:00 & buy & 16 & 1 & 118.52 & 0 & 0 & & \\
\hline 32 & 22.04.2013 23:59 & close & 16 & 1 & 127.4 & 0 & 0 & 88.8 & $10,508.1$ \\
\hline 33 & 29.04.2013 0:00 & buy & 17 & 1 & 134.42 & 0 & 0 & & \\
\hline 34 & 29.04.2013 23:59 & close & 17 & 1 & 144 & 0 & 0 & 95.8 & $10,603.9$ \\
\hline
\end{tabular}

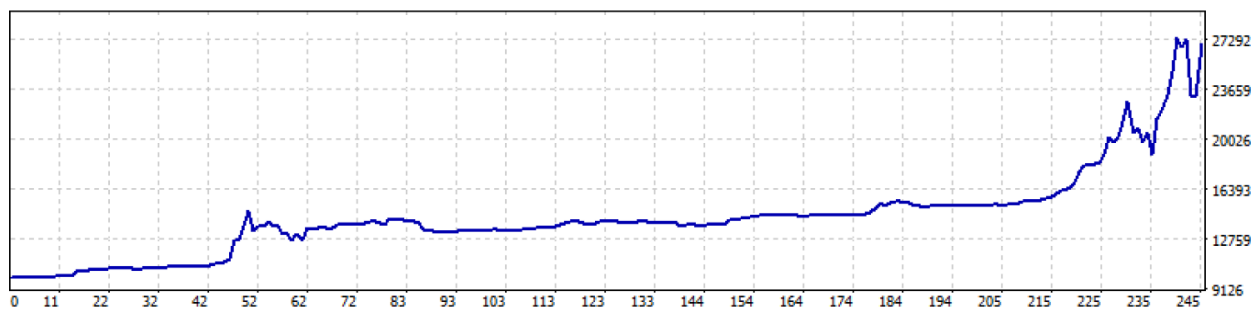

Graph A1. Graph of balance dynamics. 


\section{Appendix B: Empirical results for the day of the week effect}

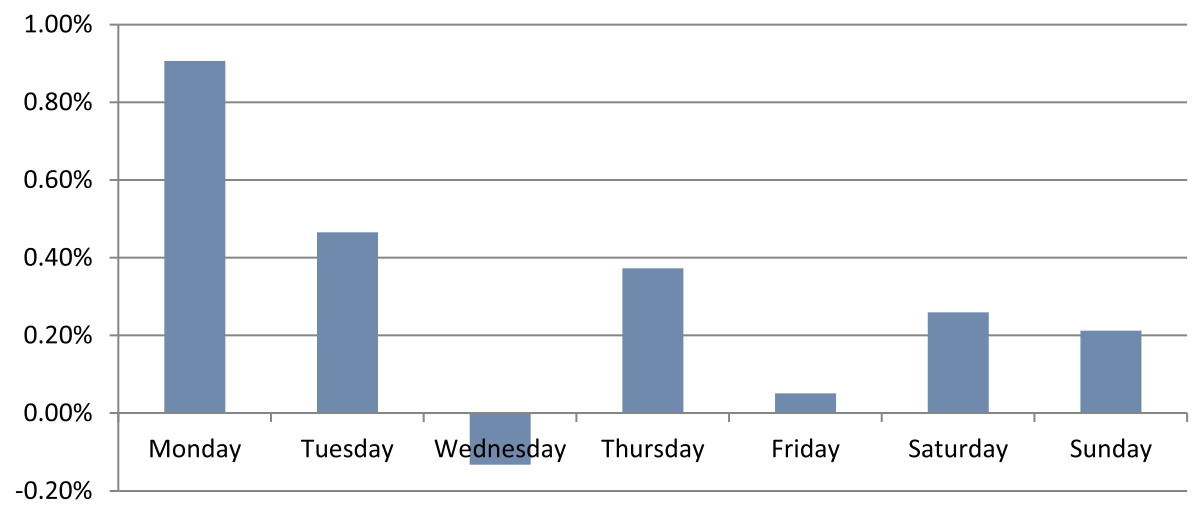

Fig. B.1. BitCoin.

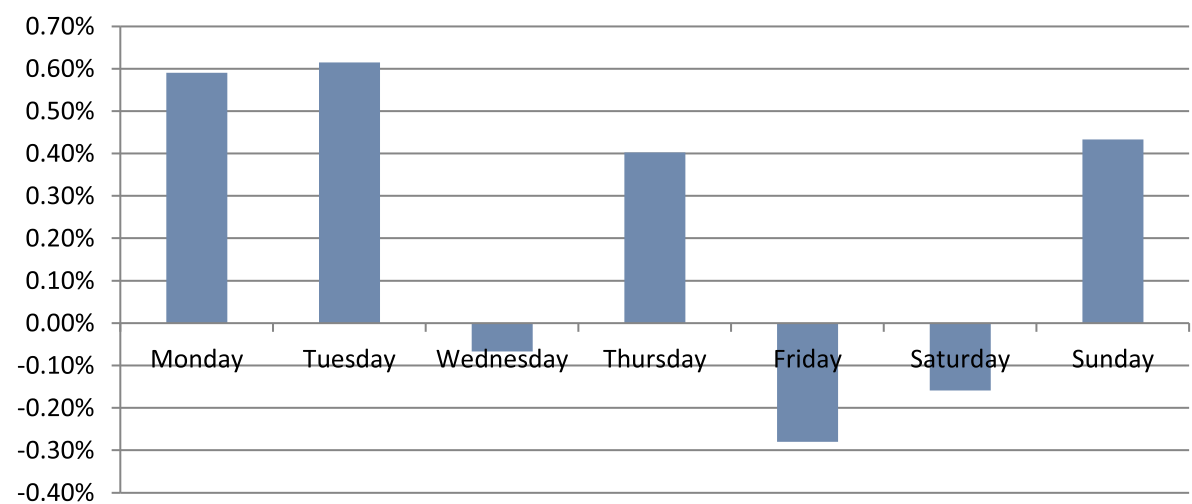

Fig. B.2. LiteCoin.

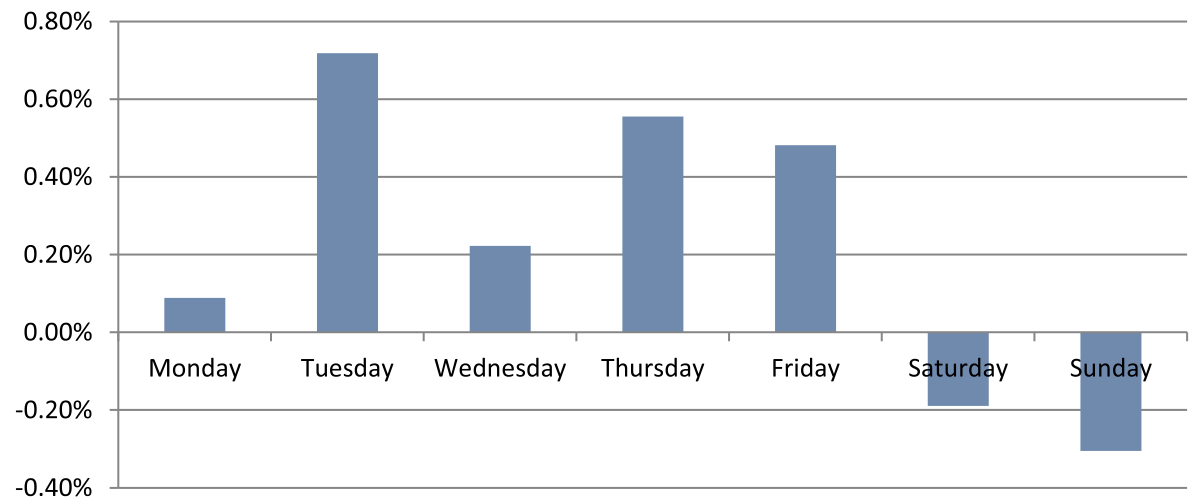

Fig. B.3. Ripple. 


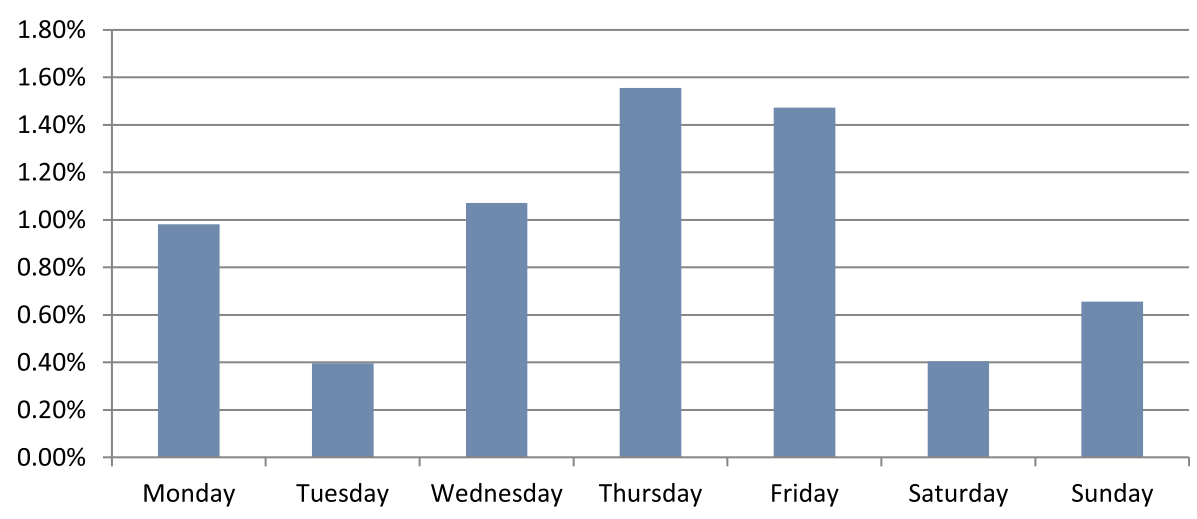

Fig. B.4. Dash.

\section{Appendix C: Parametric tests: Student's t-test}

Table C.1

T-test of the day of the week effect for BitCoin.

\begin{tabular}{|c|c|c|c|c|c|c|c|}
\hline Parameter & Monday & Tuesday & Wednesday & Thursday & Friday & Saturday & Sunday \\
\hline \multicolumn{8}{|c|}{ Population 1 (data without day of analysis) } \\
\hline Mean, $\%$ & $0.91 \%$ & $0.47 \%$ & $-0.13 \%$ & $0.37 \%$ & $0.05 \%$ & $0.26 \%$ & $0.21 \%$ \\
\hline Standard deviation, $\%$ & $4.82 \%$ & $4.05 \%$ & $4.58 \%$ & $5.05 \%$ & $4.20 \%$ & $3.60 \%$ & $3.27 \%$ \\
\hline Number of observations & 228 & 228 & 228 & 228 & 228 & 228 & 228 \\
\hline \multicolumn{8}{|l|}{ T-test results } \\
\hline$t$-criterion & 2.07 & 0.64 & -1.57 & 0.22 & -0.97 & -0.20 & -0.44 \\
\hline$t$-critical $(p=0,95)$ & 1.96 & & & & & & \\
\hline Null hypothesis & Rejected & Accepted & Accepted & Accepted & Accepted & Accepted & Accepted \\
\hline
\end{tabular}

Table C.2

T-test of the day of the week effect for LiteCoin.

\begin{tabular}{|c|c|c|c|c|c|c|c|}
\hline Parameter & Monday & Tuesday & Wednesday & Thursday & Friday & Saturday & Sunday \\
\hline \multicolumn{8}{|c|}{ Population 1 (data without day of analysis) } \\
\hline Mean,\% & $0.62 \%$ & $0.75 \%$ & $0.39 \%$ & $0.56 \%$ & $-0.16 \%$ & $-0.16 \%$ & $0.43 \%$ \\
\hline Standard deviation, $\%$ & $9.79 \%$ & $7.56 \%$ & $9.24 \%$ & $8.25 \%$ & $6.87 \%$ & $4.82 \%$ & $4.63 \%$ \\
\hline $\begin{array}{l}\text { Number of observations } \\
\text { T-test results }\end{array}$ & 188 & 188 & 188 & 188 & 188 & 188 & 188 \\
\hline t-criterion & 0.55 & 0.76 & -0.48 & 0.39 & -1.08 & -1.05 & 0.61 \\
\hline t-critical $(p=0,95)$ & 1.96 & & & & & & \\
\hline Null hypothesis & Accepted & Accepted & Accepted & Accepted & Accepted & Accepted & Accepted \\
\hline
\end{tabular}

Table C.3

T-test of the day of the week effect for Ripple.

\begin{tabular}{|c|c|c|c|c|c|c|c|}
\hline Parameter & Monday & Tuesday & Wednesday & Thursday & Friday & Saturday & Sunday \\
\hline \multicolumn{8}{|c|}{ Population 1 (data without day of analysis) } \\
\hline Mean, $\%$ & $0.26 \%$ & $0.83 \%$ & $0.41 \%$ & $1.04 \%$ & $0.86 \%$ & $-0.19 \%$ & $-0.30 \%$ \\
\hline Standard deviation,\% & $7.80 \%$ & $8.61 \%$ & $6.35 \%$ & $9.21 \%$ & $7.04 \%$ & $7.83 \%$ & $5.19 \%$ \\
\hline Number of observations & 188 & 188 & 188 & 188 & 188 & 188 & 188 \\
\hline \multicolumn{8}{|l|}{ T-test results } \\
\hline t-criterion & -0.32 & 0.89 & -0.01 & 0.62 & 0.84 & -0.80 & -1.42 \\
\hline t-critical $(p=0,95)$ & 1.96 & & & & & & \\
\hline Null hypothesis & Accepted & Accepted & Accepted & Accepted & Accepted & Accepted & Accepted \\
\hline
\end{tabular}


Table C.4

T-test of the day of the week effect for Dash.

\begin{tabular}{|c|c|c|c|c|c|c|c|}
\hline Parameter & Monday & Tuesday & Wednesday & Thursday & Friday & Saturday & Sunday \\
\hline \multicolumn{8}{|c|}{ Population 1 (data without day of analysis) } \\
\hline Mean, $\%$ & $1.00 \%$ & $0.39 \%$ & $1.12 \%$ & $1.69 \%$ & $1.40 \%$ & $0.40 \%$ & $0.66 \%$ \\
\hline Standard deviation, $\%$ & $20.11 \%$ & $11.01 \%$ & $8.26 \%$ & $8.70 \%$ & $8.04 \%$ & $9.10 \%$ & $6.91 \%$ \\
\hline $\begin{array}{l}\text { Number of observations } \\
\text { T-test results }\end{array}$ & 188 & 188 & 188 & 188 & 188 & 188 & 188 \\
\hline t-criterion & 0.04 & -0.72 & 0.23 & 0.99 & 1.11 & -0.83 & -0.53 \\
\hline t-critical $(p=0,95)$ & 1.96 & & & & & & \\
\hline Null hypothesis & Accepted & Accepted & Accepted & Accepted & Accepted & Accepted & Accepted \\
\hline
\end{tabular}

\section{Appendix D: Parametric tests: ANOVA}

Table D.1

ANOVA test of the day of the week effect for BitCoin.

\begin{tabular}{lllll}
\hline & $F$ & $p$-value & $F$ critical & Null hypothesis \\
\hline Overall & 1.39 & 0.22 & 2.10 & Accepted \\
Monday & 4.29 & 0.04 & 3.86 & Rejected \\
Tuesday & 0.29 & 0.59 & 3.86 & Accepted \\
Wednesday & 2.99 & 0.08 & 3.86 & Accepted \\
Thursday & 0.02 & 0.89 & 3.86 & Accepted \\
Friday & 1.26 & 0.26 & 3.86 & Accepted \\
Saturday & 0.49 & 0.48 & 3.86 & Accepted \\
Sunday & 0.91 & 0.34 & Accepted \\
\hline
\end{tabular}

Table D.2

ANOVA test of the day of the week effect for LiteCoin.

\begin{tabular}{lllll}
\hline & $F$ & $p$-value & $F$ critical & Null hypothesis \\
\hline Overall & 0.49 & 0.82 & 2.11 & Accepted \\
Monday & 0.27 & 0.60 & 3.87 & Accepted \\
Tuesday & 0.50 & 0.48 & 3.87 & Accepted \\
Wednesday & 0.31 & 0.58 & 3.87 & Accepted \\
Thursday & 0.10 & 0.76 & 3.87 & Accepted \\
Friday & 1.26 & 0.26 & 3.87 & Accepted \\
Saturday & 1.35 & 0.25 & 3.87 & Accepted \\
Sunday & 0.10 & 0.75 & Accepted \\
\hline
\end{tabular}

Table D.3

ANOVA test of the day of the week effect for Ripple.

\begin{tabular}{lllll}
\hline & $F$ & $p$-value & $F$ critical & Null hypothesis \\
\hline Overall & 0.56 & 0.76 & 2.11 & Accepted \\
Monday & 0.55 & 0.46 & 3.87 & Accepted \\
Tuesday & 0.27 & 0.60 & 3.87 & Accepted \\
Wednesday & 0.19 & 0.66 & 3.87 & Accepted \\
Thursday & 0.08 & 0.77 & 3.87 & Accepted \\
Friday & 0.04 & 0.85 & 3.87 & Accepted \\
Saturday & 0.89 & 0.35 & 3.87 & Accepted \\
Sunday & 2.25 & 0.13 & Accepted \\
\hline
\end{tabular}


Table D.4

ANOVA test of the day of the week effect for Dash.

\begin{tabular}{llll}
\hline & $F$ & $p$-value & $F$ critical \\
\hline Overall & 0.33 & 0.92 & 2.11 \\
Monday & 0.01 & 0.94 & 3.87 \\
Tuesday & 0.85 & 0.36 & 3.87 \\
Wednesday & 0.00 & 1.00 & 3.87 \\
Thursday & 0.60 & 0.44 & 3.87 \\
Friday & 0.26 & 0.61 & 3.87 \\
Saturday & 1.84 & 0.18 & Accepted \\
Sunday & 1.38 & 0.24 & Accepted \\
Accepted & Accepted & 3.87 \\
\end{tabular}

Appendix E: Non-parametric tests: Kruskal-Wallis and Mann-Whitney tests

Table E.1

Kruskal-Wallis and Mann-Whitney tests of the day of the week effect for BitCoin.

\begin{tabular}{llllll}
\hline Parameter & Adjusted $\mathrm{H}$ & d.f. & $P$ value & Critical value & Null hypothesis \\
\hline Overall & 9.22 & 6 & 0.16 & 12.60 & Accepted \\
Monday & 7.25 & 1 & 0.01 & 3.84 & Rejected \\
Tuesday & 4.49 & 1 & 0.03 & 3.84 & Rejected \\
Wednesday & 1.97 & 1 & 0.16 & 3.84 & Accepted \\
Thursday & 0.07 & 1 & 0.78 & 3.84 & Accepted \\
Friday & 0.02 & 1 & 0.89 & 3.84 & Accepted \\
Saturday & 7.92 & 1 & 0.00 & 3.84 & Rejected \\
Sunday & 7.38 & 1 & 0.01 & Rejected \\
\hline
\end{tabular}

Table E.2

Kruskal-Wallis and Mann-Whitney tests of the day of the week effect for LiteCoin.

\begin{tabular}{|c|c|c|c|c|c|}
\hline Parameter & Adjusted $\mathrm{H}$ & d.f. & $P$ value & Critical value & Null hypothesis \\
\hline Overall & 5.26 & 6 & 0.51 & 12.60 & Accepted \\
\hline Monday & 0.06 & 1 & 0.80 & 3.84 & Accepted \\
\hline Tuesday & 0.24 & 1 & 0.63 & 3.84 & Accepted \\
\hline Wednesday & 1.94 & 1 & 0.16 & 3.84 & Accepted \\
\hline Thursday & 0.15 & 1 & 0.69 & 3.84 & Accepted \\
\hline Friday & 0.09 & 1 & 0.76 & 3.84 & Accepted \\
\hline Saturday & 1.38 & 1 & 0.24 & 3.84 & Accepted \\
\hline Sunday & 2.10 & 1 & 0.15 & 3.84 & Accepted \\
\hline
\end{tabular}

Table E.3

Kruskal-Wallis and Mann-Whitney test of the day of the week effect for Ripple.

\begin{tabular}{lllll}
\hline Parameter & Adjusted H & d.f. & $P$ value & Critical value \\
\hline Overall & 10.12 & 6 & 0.12 & 12.60 \\
Monday & 0.31 & 1 & 0.58 & 3.84 \\
Tuesday & 0.91 & 1 & 0.34 & 3.84 \\
Wednesday & 0.46 & 1 & 0.50 & 3.84 \\
Thursday & 0.80 & 1 & 0.37 & 3.84 \\
Friday & 1.82 & 1 & 0.18 & 3.84 \\
Saturday & 3.92 & 1 & 0.05 & 3.84 \\
Sunday & 1.70 & 1 & 0.19 & Accepted \\
Accepted & & Accepted & 3.84 \\
\hline
\end{tabular}


Table E.4

Kruskal-Wallis and Mann-Whitney tests of the day of the week effect for Dash.

\begin{tabular}{|c|c|c|c|c|c|}
\hline Parameter & Adjusted H & d.f. & $P$ value & Critical value & Null hypothesis \\
\hline Overall & 9.22 & 6 & 0.16 & 12.60 & Accepted \\
\hline Monday & 2.68 & 1 & 0.10 & 3.84 & Accepted \\
\hline Tuesday & 4.49 & 1 & 0.03 & 3.84 & Rejected \\
\hline Wednesday & 1.97 & 1 & 0.16 & 3.84 & Accepted \\
\hline Thursday & 0.07 & 1 & 0.78 & 3.84 & Accepted \\
\hline Friday & 0.02 & 1 & 0.89 & 3.84 & Accepted \\
\hline Saturday & 7.92 & 1 & 0.00 & 3.84 & Rejected \\
\hline Sunday & 7.38 & 1 & 0.01 & 3.84 & Rejected \\
\hline
\end{tabular}

Appendix F: Regression analysis with dummy variables

Table F.1

Regression analysis with dummy variables of the day of the week effect for crypto currencies (BitCoin, LiteCoin, Ripple and Dash)."

\begin{tabular}{|c|c|c|c|c|}
\hline Parameter & BitCoin & LiteCoin & Ripple & Dash \\
\hline \multirow[t]{2}{*}{ Monday $\left(\mathrm{a}_{0}\right)$} & 0.0091 & 0.0059 & 0.0009 & 0.0099 \\
\hline & $(0.002)$ & $(0.274)$ & $(0.859)$ & $(0.225)$ \\
\hline \multirow[t]{2}{*}{ Tuesday $\left(\mathrm{a}_{1}\right)$} & -0.0044 & 0.0002 & 0.0063 & -0.0059 \\
\hline & $(0.299)$ & $(0.974)$ & $(0.372)$ & $(0.609)$ \\
\hline \multirow[t]{2}{*}{ Wednesday $\left(\mathrm{a}_{2}\right)$} & -0.0104 & -0.0066 & 0.0013 & 0.0009 \\
\hline & $(0.014)$ & $(0.390)$ & $(0.850)$ & $(0.937)$ \\
\hline \multirow[t]{2}{*}{ Thursday $\left(\mathrm{a}_{3}\right)$} & -0.0054 & -0.0019 & 0.0047 & 0.0058 \\
\hline & $(0.209)$ & $(0.806)$ & $(0.509)$ & $(0.616)$ \\
\hline \multirow[t]{2}{*}{ Friday $\left(a_{4}\right)$} & -0.0086 & -0.0087 & 0.0039 & 0.0049 \\
\hline & $(0.044)$ & $(0.255)$ & $(0.578)$ & $(0.667)$ \\
\hline \multirow[t]{2}{*}{ Saturday $\left(a_{5}\right)$} & -0.0065 & -0.0075 & -0.0028 & -0.0058 \\
\hline & $(0.104)$ & $(0.327)$ & $(0.694)$ & $(0.613)$ \\
\hline \multirow[t]{2}{*}{ Sunday $\left(\mathrm{a}_{6}\right)$} & -0.0070 & -0.0016 & 0.0040 & -0.0033 \\
\hline & $(0.081)$ & $(0.837)$ & $(0.577)$ & $(0.775)$ \\
\hline$F$-test & $1.38(0.13)$ & $0.48(0.82)$ & $0.59(0.73)$ & $0.34(0.91)$ \\
\hline Multiple R & 0.07 & 0.04 & 0.05 & 0.04 \\
\hline Anomaly & Confirmed & Not confirmed & Not confirmed & Not confirmed \\
\hline
\end{tabular}

* P-values are in parentheses.

Appendix G: Additional tests of the Monday effect for the case of Bitcoin: Monday returns vs average returns on all days except Monday and Sunday

\section{Parametric tests: Student's $t$-test}

Table G.1

T-test of the day of the week effect for BitCoin: Monday vs all days except Monday and Sunday.

\begin{tabular}{lll}
\hline Parameter & Monday & All days except Monday and Sunday \\
\hline Mean, $\%$ & $0.91 \%$ & $0.20 \%$ \\
Standard deviation, $\%$ & $4.82 \%$ & $4.32 \%$ \\
Number of observations & 228 & 1140 \\
$t$-criterion & 2.04 & \\
$t$-critical $(p=0,95)$ & 1.96 & \\
Null hypothesis & Rejected & \\
\hline
\end{tabular}

Table G.2

ANOVA test of the day of the week effect for BitCoin: Monday vs all days except Monday and Sunday.

\begin{tabular}{llll}
\hline$F$ & $p$-value & $F$ critical & Null hypothesis \\
\hline 4.28 & 0.04 & 3.86 & Rejected \\
\hline
\end{tabular}




\section{Parametric tests: ANOVA}

\section{Non-parametric tests: Mann-Whitney tests.}

\section{Regression analysis with dummy variables.}

Table G.3

Mann-Whitney test for BitCoin: Monday vs all days except Monday and Sunday.

\begin{tabular}{lllll}
\hline Adjusted $\mathrm{H}$ & d.f. & P value & Critical value & Null hypothesis \\
\hline 3.01 & 1 & 0.08 & 3.84 & Accepted \\
\hline
\end{tabular}

\section{Table G.4}

Regression analysis with dummy variables: Monday vs all days except Monday and Sunday.*

\begin{tabular}{ll}
\hline Parameter & BitCoin \\
\hline Non-Monday $\left(\mathrm{a}_{0}\right)$ & $0.0020(0.398)$ \\
Monday $\left(\mathrm{a}_{1}\right)$ & $0.0070(0.035)$ \\
F-test & $4.28(0.04)$ \\
Multiple R & 0.10 \\
Anomaly & Confirmed
\end{tabular}

* P-values are in parentheses.

\section{Average analysis}

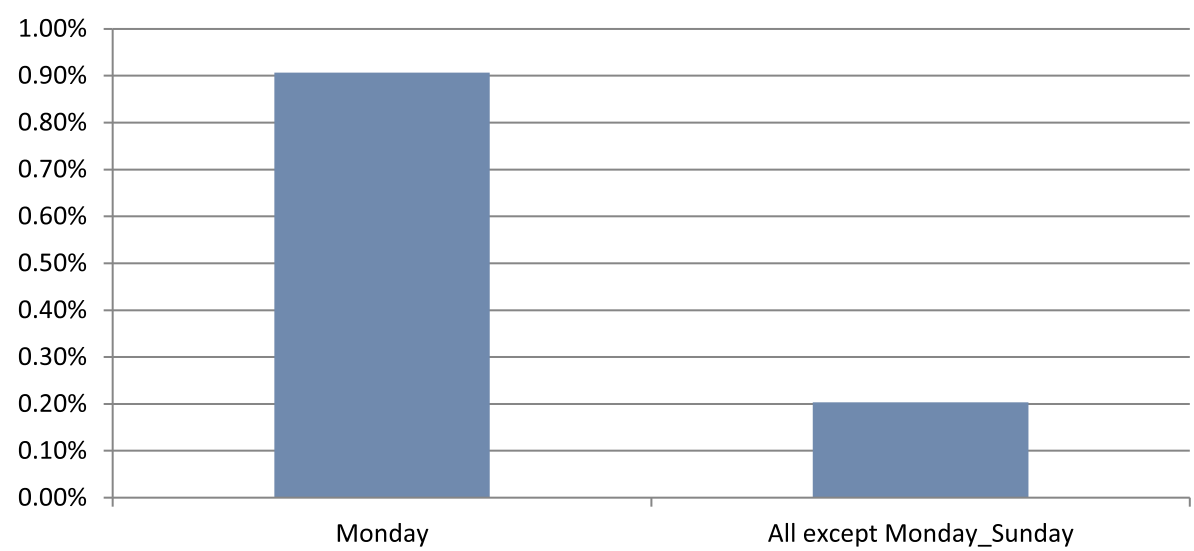

Fig. G.1. Average returns of BitCoin: Monday vs all days except Monday and Sunday.

\section{References}

Ariel, R., 1990. High stock returns before holidays: existence and evidence on possible causes. J. Financ. 45 (5), $1611-1626$.

Bartos, J., 2015. Does Bitcoin follow the hypothesis of efficient market? Int. J. Econ. Sci. IV (2), 10-23.

Brown, W.L., 2014. An Analysis of Bitcoin Market Efficiency Through Measures of Short-Horizon Return Predictability and Market Liquidity. CMC Senior Theses. Paper 864. http://scholarship.claremont.edu/cmc_theses/864.

Caporale, G.M., Plastun, A., 2017. Calendar anomalies in the Ukrainian stock market. Invest. Manag. Financ. Innov. Int. Res. J. 14 (1), $104-114$.

Caporale, G.M., Gil-Alana, L., Plastun, A., Makarenko, I., 2017. The weekend effect: a trading robot and fractional integration analysis. Int. J. Bonds Deriv. 3 (2), 114-131.

Caporale, G.M., Gil-Alana, L., Plastun, A, 2016. The weekend effect: an exploitable anomaly in the Ukrainian stock market? J. Econ. Stud. 43 (6), 954-965. https://doi. org/10.1108/JES-09-2015-0167.

Carrick, J., 2016. Bitcoin as a complement to emerging market currencies. Emerg. Markets Financ. Trade 52 (2016), $2321-2334$.

Cheung, A., Roca, E., Su, J.-J., 2015. Crypto-currency bubbles: an application of the Phillips-Shi-Yu (2013) methodology on Mt. Gox Bitcoin prices. Appl. Econ. 47, 2348-2358. 
Cross, F., 1973. The behavior of stock prices on fridays and mondays. Financ. Anal. J. 29 (6), 67-69.

Dwyer, G.P., 2014. The economics of Bitcoin and similar private digital currencies. J. Financ. Stab. 17, 81-91.

Fama, E., 1965. The behavior of stock-market prices. J. Bus. 38 (1), 34-105.

Fields, M., 1931. Stock prices: a problem in verification. J.Bus. 4, 415-418.

Fortune, P. (1998), Weekends can be rough: revisiting the weekend effect in stock prices. Federal Reserve Bank of Boston. Working Paper No. 98-106.

French, K., 1980. Stock returns and the weekend effect. J. Financ. Econ. 8 (1), 55-69.

Gibbons, M., Hess, P., 1981. Day effects and asset returns. J. Bus. 54 (4), 579-596.

Halaburda, H. and N. Gandal (2014), Competition in the Cryptocurrency Market. NET Institute Working Paper No. 14-17. Available at SSRN: https://ssrn.com/ abstract $=2506463$.

Hsaio, P., Solt, M., 2004. Is the weekend effect exploitable? Invest. Manag. Financ. Innov. 1, 53.

Jensen, M., 1978. Some anomalous evidence regarding market efficiency. J. Financ. Econ. 6 (2-3), 95-101.

Kurihara, Y., Fukushima, A., 2017. The market efficiency of Bitcoin: a weekly anomaly. Perspect. J. Appl. Financ. Bank. 7 (3), $57-64$.

Samuelson, P., 1965. Proof That Properly anticipated prices fluctuate randomly. Ind. Manag. Rev. 6 (2), 41-49.

Rogalski, R.J., 1984. New findings regarding day-of-the-week returns over trading and non-trading periods: a note. J. Financ. 39 (December), $1603-1614$.

Schwert, G.W., 2003. Anomalies and market efficiency. Handbook of the Economics of Finance. Elsevier Science B.V. Ch.5, pp. 937-972.

Sias, R.W., Starks, L.T., 1995. The day-of-the week anomaly: the role of institutional investors. Financ. Anal. J. 51 (3), $58-67$.

Singal, V., Tayal, J., 2014. 2014. Does Unconstrained Short Selling Result in Unbiased Security Prices? Evidence from the Weekend Effect in Futures Markets (May 5 , 2014). Available at SSRN: . http://ssrn.com/abstract $=2433233$.

Smirlock, M., Starks, L., 1986. Day-of-the-week and intraday effects in stock returns. J. Financ. Econ. 17, $197-210$.

Urquhart, A., 2016. The inefficiency of Bitcoin. Econ. Lett. 148, 80-82. 